Article

\title{
The Stability of Temporary Restorations Fabricated on a Healing Cap for Immediate Loading: An In Vitro Study
}

\author{
Sangho Jun ${ }^{1}$, Hyonseok Jang ${ }^{2}$, Enji Cheon ${ }^{3}$, MinJu Kim ${ }^{3}{ }^{\circledR}$, Sungwon Ju ${ }^{3}$ and Jinsoo Ahn ${ }^{3, *(D)}$ \\ 1 Department of Oral and Maxillofacial Surgery, Anam Hospital, Korea University, 73 Inchon-ro, \\ Seongbuk-gu, Seoul 02841, Korea; omfs.junsang@gmail.com \\ 2 Department of Oral and Maxillofacial Surgery, Ansan Hospital, Korea University, 123 Jeokgeum-ro, \\ Danwon-gu, Ansan 15355, Gyeonggi Province, Korea; omfs1109@korea.ac.kr \\ 3 Dental Research Institute and Department of Dental Biomaterials Science, School of Dentistry, \\ Seoul National University, 101 Daehak-ro, Jongno-gu, Seoul 03080, Korea; enji1229@snu.ac.kr (E.C.); \\ kkotemandu@snu.ac.kr (M.K.); swju27@snu.ac.kr (S.J.) \\ * Correspondence: ahnjin@snu.ac.kr; Tel.: +82-2-740-8691
}

Received: 19 October 2018; Accepted: 13 November 2018; Published: 15 November 2018

Featured Application: The result of this paper provides clinical guidance for the use of interim restoration, which protects a dental implant and the surrounding tissue by distributing unfavorable stress over the implant and the bone surface.

\begin{abstract}
The aim of this study was to analyze the load distribution of interim restorations using healing cap during immediate loading implant treatment in vitro. A total of 29 models with interim restorations which were fabricated with healing cap were selected. The pull-out strength was measured with a used healing cap and new healing cap. The compressive strength and sinking distance were also measured. The pull-out strength of interim restoration showed lower value (max. $29.8 \mathrm{~N}$ ) compared to the natural bite force. The sinking amounts were larger than normal tooth sinking. The sinking amounts of interim restorations fabricated on a healing cap were roughly 3 times $(0.3-0.5 \mathrm{~mm}$ under $450 \mathrm{~N})$ those of normal teeth. The interim restoration on plastic healing cap would be useful for immediate loading implant treatment.
\end{abstract}

Keywords: bite force; dental implant; immediate dental implant loading; temporary dental restoration

\section{Introduction}

Improvements in implant surface design and surgical technique have led to modifications in the traditional treatment concept of implant loading time and have increased the rate of success.

The success of immediate-loading implants, in which the force is loaded within one week of the surgery, is determined predominantly by the primary stability and osseointegration during the initial healing period. The initial stability of the installed implant is primarily dominated by the mechanical stability rather than the biological stability [1]. This tendency is reversed as the bone undergoes a phase of formation and remodeling. A temporary decrease in stability is noted during this transition, and overloaded or unfavorable forces applied to the implant during this phase of instability hinder successful osseointegration [2].

Kan et al. reported a 100\% survival rate of single immediate-loading implants on the anterior maxillary region, which can be largely attributed to the strict inclusion and exclusion criteria that prevented failures [3]. Despite the challenges associated with immediate-loading implants, studies reporting success rates close to $100 \%$ have included high primary stability with insertion 
torque more than $30 \mathrm{Ncm}$ as one of the indications for applying immediate loading [4-6]. The primary stability is an essential factor in planning immediate-loading as the treatment modality [7].

Brunksi et al. reported that micro-motion of more than $100 \mu \mathrm{m}$ interfered with direct osseointegration, and Pillar et al. noted that micro-mobility of more than $150 \mu \mathrm{m}$ caused fibrous tissue formation whereas $28 \mu \mathrm{m}$ or less did not influence osseointegration in any way. In contrast, Wolff's law states that increases in stress stimulate new bone formation, and decreased stress leads to bone loss. Thus, controlled micro mechanical stress through temporary restorations during the initial healing phase may be a useful stimulant for bone formation [8-10].

Provisional restorations fabricated with acrylic or composite materials provide a means of both functional and esthetic rehabilitation for a certain period of time in immediate-loading treatment [11].

A study using finite element analysis revealed that the distribution of occlusal force loaded on the provisional restoration varies according to the material of the fitness of the restoration, which then delivers the force to the retention screw and the underlying bone tissue [12].

A customized healing cap simplifies the fabrication of acrylic provisional restorations over the cap while also allowing easy removal from the abutment with appropriate fitting at the margin. Hence, it is used in immediate-loading cases; however, studies of its response to occlusal loading is scarce.

The purpose of this study was to analyze the load distribution of provisional restorations using a healing cap during immediate-loading implant treatment.

\section{Materials and Methods}

Twenty-nine post-treatment models with provisional restorations fabricated with a healing cap (TS Rigid Protect Cap, Osstem, Busan, Korea) during immediate-loading implant treatment at the Department of Dentistry, Korea University Anam Hospital were selected. The healing cap was $1.3 \mathrm{~mm}$ longer and $0.4 \mathrm{~mm}$ wider than the abutment underneath. The types of prostheses included 13 one-unit, 9 two-unit and 7 three-unit restorations for a total of 52 implants. The implants were placed using the submerged approach with 2-piece configurations, which comprise separate abutment and fixture (TS III Ø4.5, Osstem, Busan, Korea).

The provisional restorations were directly fabricated chair-side with acrylic resin (Alike, GC, Tokyo, Japan) with a clear shell fabricated from a study model prior to surgery and delivered to patients immediately following implant installation (Figure 1). All selected cases were completed to the final restorations and showed desirable clinical results (Figure 2). Restoration scheme for the provisional restorations in the anterior area was established so no contact is made during protrusion or lateral movement of the mandible. The restoration scheme in the posterior area was that there was no contact in eccentric movement while $50 \mu \mathrm{m}$ gap occurs during centric movement.
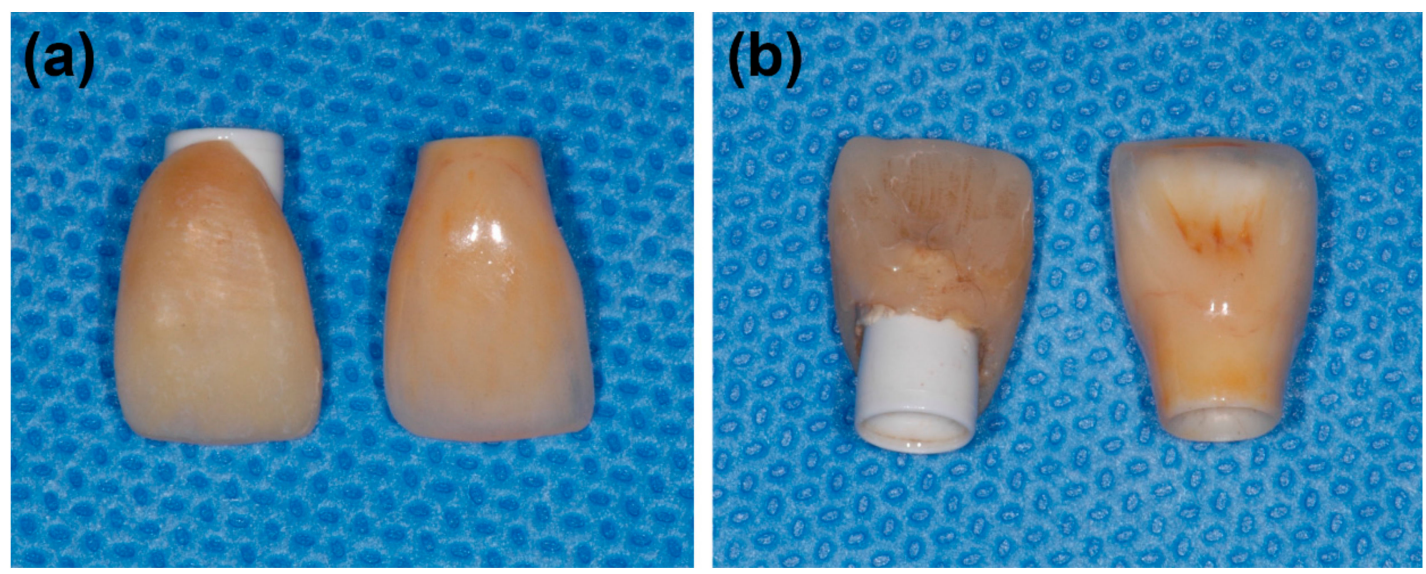

Figure 1. Labial (a) and lingual (b) view of provisional restoration fabricated on the healing cap and final restoration. 

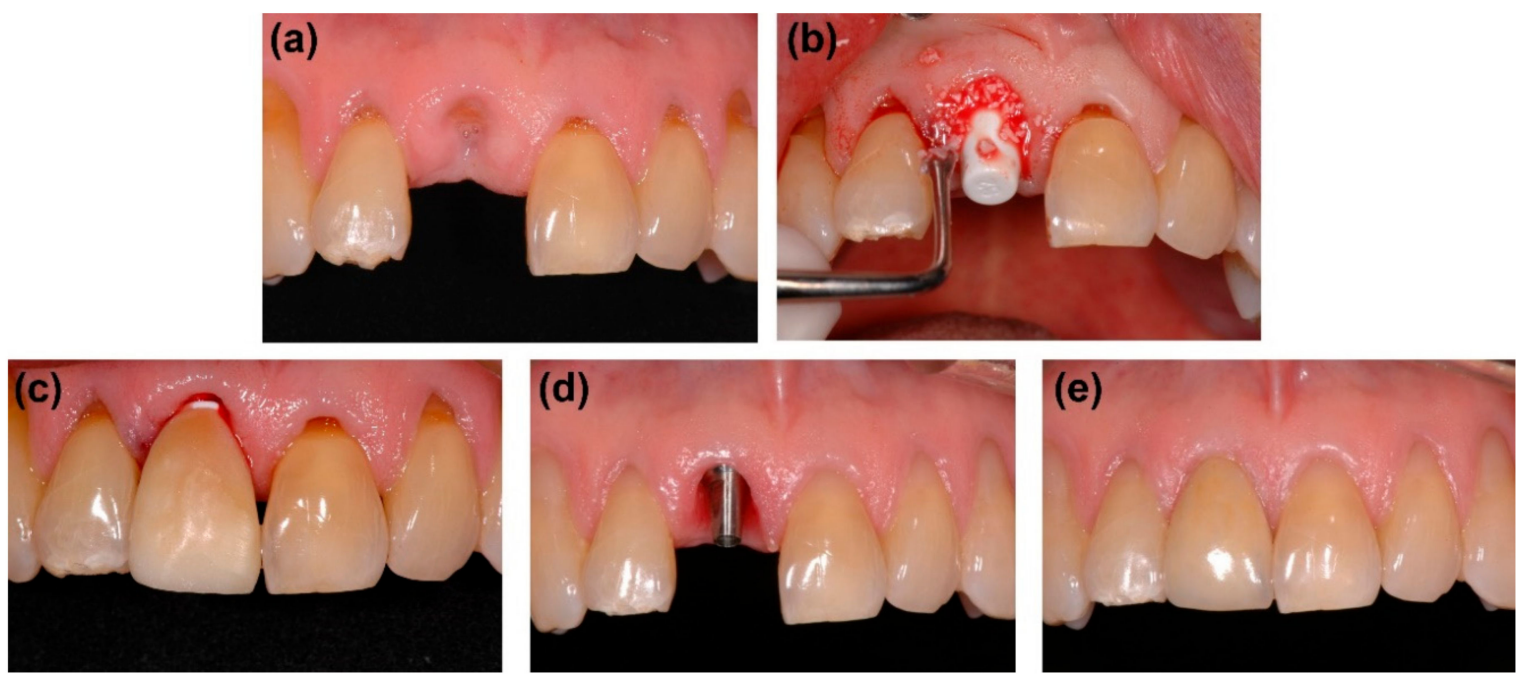

Figure 2. Treatment procedure of a one-unit case showing before the treatment (a), immediately after surgery with healing cap (b), provisional restoration on healing cap (c), abutment placement after healing of surrounding tissues (d), and final restoration (e).

\subsection{The Pull-Out Strength Test}

\subsubsection{With Healing Cap}

The provisional restorations were removed and collected from patients' oral cavities after use. A hook made from a 1.05-mm wire was attached to the restoration at its midmost point buccolingually and mesiodistally with acrylic resin to measure the tensile strength. In the case of two-unit restorations, the hook was attached on the connector part, and in three-unit restorations, the hook was attached to the tooth in the middle. The tensile strength was evaluated via the universal testing machine (Instron 4465, Instron Corporation, Norwood, MA, USA) with $1 \mathrm{~mm} / \mathrm{min}$ crosshead speed. The pull-out strength was determined as the maximum tensile strength after removal of the restoration (Figure 3).
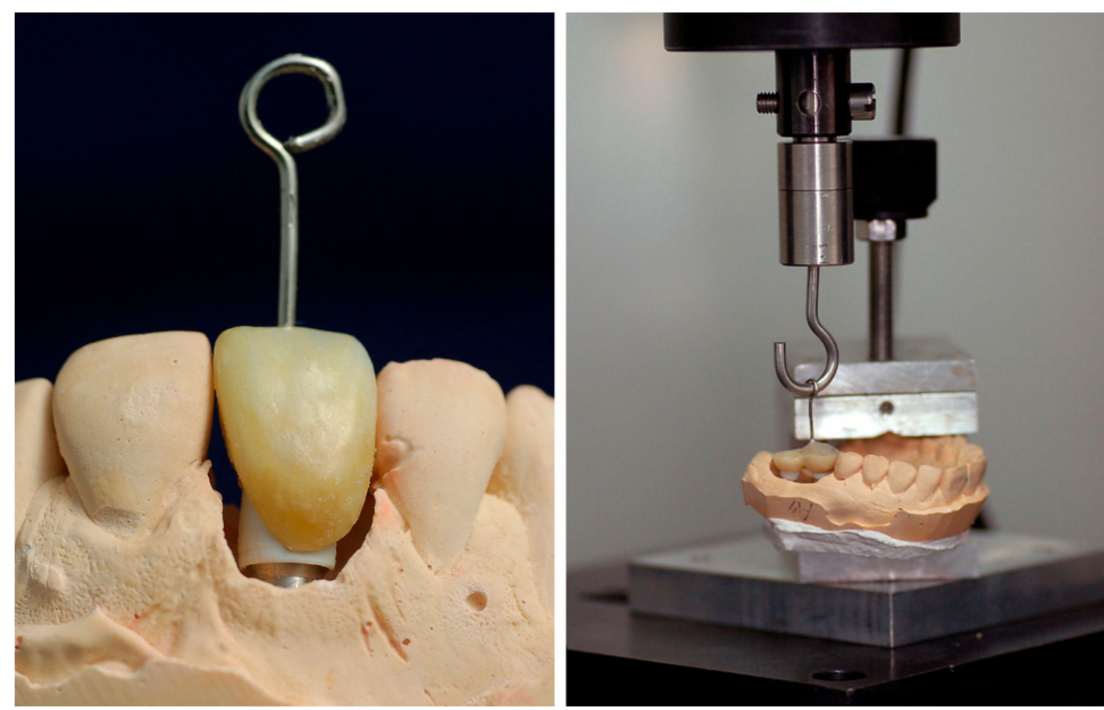

Figure 3. Provisional restoration (a) and pull-out strength test with the testing machine (b).

\subsubsection{New Healing Cap}

Specimens were fabricated using new healing caps identical to the ones used for patients. The specimens were not in the restorative form; however, the acrylic resin was added on the healing cap in the same manner as the ones used for clinical situations in order to attach the hook for strength 
measurement. The specimens of two- and three-unit restorations had their healing caps assembled together with acrylic resin to maintain their forms. The pull-out strength was determined with the same method as the initial healing cap.

\subsection{The Compressive Strength Test and Measurement of Displacement}

Compressive strength and sinking were measured using a universal testing machine with the provisional restoration set on the model at $1 \mathrm{~mm} / \mathrm{min}$ crosshead speed. The compressive strength was determined to be the maximum load after complete fracture of the restoration.

Sinking was defined as the total distance the crosshead moved from the point of contact with provisional restoration to the point of fracture of the restoration during the compressive fracture strength evaluation.

\subsection{Statistical Analysis}

The pull-out strength, compressive strength and sinking data were stratified according to the number of units of restoration and were compared using Kruskal-Wallis test (SPSS ver. 20, IBM, Chicago, IL, USA).

\section{Results}

All twenty-nine provisional restorations fabricated with a healing cap remained at their original sites and there was no dislodge of any component during the healing phase. In evaluation of the pull-out strength of the healing caps, the values exhibited an incremental trend from one-unit to three-unit restorations; one-unit restorations had a pull-out strength of 7.8-14.8 N, two-unit restorations, 10.4-13.9 $\mathrm{N}$ and three-unit restorations, $16.7-20.6 \mathrm{~N}$. There were significant differences between the unit groups $(p<0.05)$. The average and standard deviation are shown in Table 1.

Table 1. Pull-out strength of the healing caps.

\begin{tabular}{cccc}
\hline \multicolumn{2}{c}{ Group } & $\begin{array}{c}\text { Mean } \\
\text { (N) }\end{array}$ & Std \\
\hline \multirow{4}{*}{ New } & 1 unit & $14.2^{\mathrm{a}}$ & 0.9 \\
& 2 unit & $27.8^{\mathrm{b}}$ & 1.6 \\
& 3 unit & $29.8^{\mathrm{b}}$ & 5.2 \\
\hline \multirow{4}{*}{ Used } & 1 unit & $10.2^{\mathrm{a}}$ & 2.5 \\
& 2 unit & $12.0^{\mathrm{b}}$ & 1.1 \\
& 3 unit & $18.5^{\mathrm{c}}$ & 1.5 \\
\hline
\end{tabular}

a,b,c Different superscripts in each cell indicate a statistical differences $(p<0.05)$, and identical superscripts indicate no statistical difference within the croup.

Pull-out strength values of the new healing caps were shown to be 12.0-15.0 N for one-unit, 26.4-31.5 N for two-unit and 22.9-38.3 N for three-unit restorations. The incremental trend as the unit increased was also shown with the new healing caps. There was a significant difference between the one-unit and two- and three-unit groups $(p<0.05)$, whereas no statistical differences were seen between the two-unit and three-unit groups. The average and standard deviation are shown in Table 1 .

The results of compressive fracture strength of the used provisional restorations are shown in Table 2. The two-unit group showed the lowest values with a range of 882.0-1267.1 N, the one-unit group ranged from 1017.2-1477.8 $\mathrm{N}$ and the three-unit group showed the highest values, ranging 1278.9-1759.1 N. There were statistically significant differences between the groups $(p<0.05)$, and the mean and standard deviations are shown in Table 2. 
Table 2. Comprehensive fracture strength of used provisional restorations.

\begin{tabular}{cccc}
\hline Unit & Mean Compressive Strength (N) & Standard Deviation & Mean Sinking (mm) \\
\hline 1 unit & $1274.9^{\mathrm{a}}$ & 83.3 & 0.69 \\
2 unit & $1039.8^{\mathrm{b}}$ & 82.3 & 0.60 \\
3 unit & $1587.6^{\mathrm{c}}$ & 267.5 & 0.78 \\
\hline
\end{tabular}

$a, b, c$ Different superscripts in each cell indicate a statistical differences $(p<0.05)$.

The sinking was recorded as the maximum force at the point of restoration fracture during compressive strength evaluation. The trends in this test were similar to those of the compressive strength test, with values increasing in order of two-unit, one-unit and then three-unit groups. The two-unit group showed the lowest values of $0.49 \mathrm{~mm}$ to $0.78 \mathrm{~mm}$, the one-unit group had values of $0.50 \mathrm{~mm}$ to $0.90 \mathrm{~mm}$, and the three-unit group showed values of $0.66 \mathrm{~mm}$ to $0.93 \mathrm{~mm}$. The mean and standard deviation are shown in Table 2.

Figure 4 shows the representative load-displacement graph of one-unit, two-unit and three-unit provisional restorations.

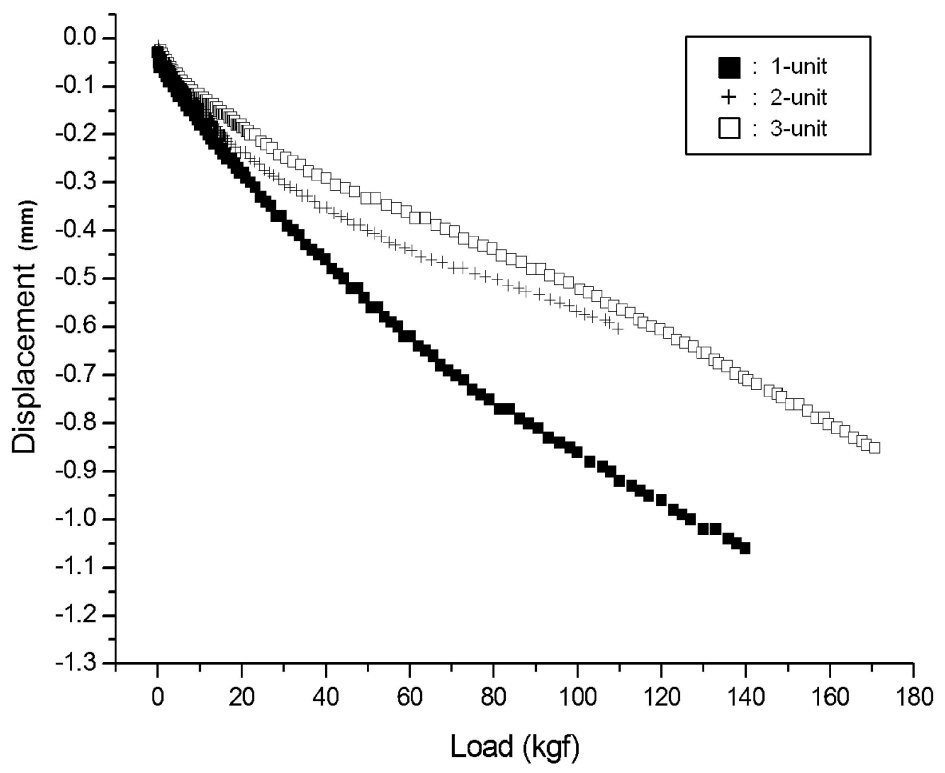

Figure 4. Load displacement of provisional restorations.

\section{Discussion}

Occlusal forces affect the bone surrounding an oral implant. Mechanical stress can have both positive and negative consequences for bone tissue and maintaining the osseointegration of an oral implant [10]. An adequate magnitude of immediate load can promote peri-implant osteogenesis, while excessive load can cause breakdown of peri-implant tissue [13].

Immediate loading may reduce the treatment duration and prevent the resorption of the bone surrounding extraction sockets; however, a cautious approach should be taken as overloading may lead to failure of the implant with elongated treatment duration and may lead to dystrophy of the surrounding tissues [14].

The major difference between natural teeth and dental implants is the presence of the periodontal ligament, which effectively distributes the dynamic load in natural teeth.

Periodontal tissues contain various load-distributing components such as minerals, fibrillar proteins and globular proteins. The fibrillar proteins interact with globular proteins, interstitial fluid and blood [15-17]. These components with their respective constitutive properties could have different load-bearing responses individually or combined, depending on the rate of loading [18]. 
Thus, the existence of shock absorbing before obtaining firm osseointegration might effectively distribute the loading to the implant and make immediate loading more successful.

The present study evaluated provisional restoration using a healing cap for load buffering. Since this was an in vitro study, conditions that may cause spontaneous dislodge of provisional restorations, such as water leakage in cement, did not occur. If such displacement occurs in clinic, the dentist may simply check the occlusion and reattach provisional restoration and the implant will be safe. The results revealed that provisional restorations showed sinking tendencies to certain extents until the point of fracture. Considering the range of sinking in a natural tooth is $0.05-0.1 \mathrm{~mm}$ under $45 \mathrm{kgf}$, the present study showed $0.3-0.5 \mathrm{~mm}$ sinking under $45 \mathrm{kgf}$, which exhibits the protection capability of a plastic fabricated cap applied on implants between natural teeth [19].

The results of the study showed detachment in all temporary restorations fabricated with plastic caps under a force less than $30 \mathrm{~N}$. This force may be considered relatively weak compared to the normal bite force of humans. Although there are differences in the direction of the force, the fall off of the temporary restoration may prevent the adverse external force. Paying careful attention to the occlusal scheme and characteristics of force is especially crucial in the case of screw-retained implants, as force cannot be dispersed or lost through the loosening of healing cap, but rather passing directly down the body of implant. This creates an adverse environment that may eventually cause ossteointegration failure of implant.

Considering that the maximal bite forces on posterior teeth are $330-800 \mathrm{~N}$, the fracture strength shown in the present study had the capacity to withstand the subject's occlusal forces [20-25].

The notably low fracture resistance in two-unit restorations may be explained by our selection of the point part as the point of force loaded rather than directly on the abutment. Also, there might be limitations in this study that prevented perfect simulation of clinical situations. Further studies should include the standardized method of force loading.

\section{Conclusions}

In conclusion, the pull-out strengths of used and new provisional restorations were less (max. $29.8 \mathrm{~N}$ ) than the natural bite force. The sinking amounts of provisional restorations fabricated on a healing cap were roughly 3 times $(0.3-0.5 \mathrm{~mm}$ under $45 \mathrm{kgf})$ those of normal teeth. Within the limitations of the current experimental settings of this study, it can be concluded that provisional restoration fabricated on a plastic healing cap may protect implant fixtures against harmful loading for successful immediate loading.

Author Contributions: Conceptualization, S.J. (Sangho Jun); Methodology, S.J. (Sungwon Ju); Validation, H.J.; Formal Analysis, E.C.; Investigation, E.C.; Data Curation, S.J. (Sungwon Ju); Writing-Original Draft, M.K.; Visualization, M.K.; Supervision, J.A.; Project Administration, S.J. (Sangho Jun); Funding Acquisition, J.A.

Funding: This research was funded by Basic Science Research Program through the National Research Foundation of Korea (NRF) funded by the Ministry of Education and the Ministry of Science, ICT \& Future Planning (NRF-2017R1D1A1B03028418 and NRF-2017M3A9F1027902) and a Korea University Grant.

Conflicts of Interest: The authors declare no conflict of interest.

\section{References}

1. Raghavendra, S.; Wood, M.C.; Taylor, T.D. Early wound healing around endosseous implants: A review of the literature. Int. J. Oral Maxillofac. Implant. 2005, 20, 425-431.

2. West, J.D.; Oates, T.W. Identification of stability changes for immediately placed dental implants. Int. J. Oral Maxillofac. Implant. 2007, 22, 623-630.

3. Kan, J.Y.; Rungcharassaeng, K.; Umezu, K.; Kois, J.C. Dimensions of peri-implant mucosa: An evaluation of maxillary anterior single implants in humans. J. Periodontol. 2003, 74, 557-562. [CrossRef] [PubMed]

4. Achilli, A.; Tura, F.; Euwe, E. Immediate/early function with tapered implants supporting maxillary and mandibular posterior fixed partial dentures: Preliminary results of a prospective multicenter study. J. Prosthet. Dent. 2007, 97, S52-S58. [CrossRef] 
5. Calandriello, R.; Tomatis, M.; Rangert, B. Immediate functional loading of Branemark System implants with enhanced initial stability: A prospective 1- to 2-year clinical and radiographic study. Clin. Implant. Dent. Relat. Res. 2003, 5 (Suppl. 1), 10-20. [CrossRef]

6. Shibly, O.; Kutkut, A.; Patel, N.; Albandar, J.M. Immediate implants with immediate loading vs. conventional loading: 1-year randomized clinical trial. Clin. Implant. Dent. Relat. Res. 2012, 14, 663-671. [CrossRef] [PubMed]

7. Yeom, J.; Kwak, O.; Jun, S.; Choi, Y.; Kwon, J. Bone formation and stability changes of the immediately loaded implants by crown units. J. Korean Acad. Implant. Dent. 2011, 30, 11.

8. Frost, H.M. Perspectives: bone's mechanical usage windows. Bone Miner. 1992, 19, 257-271. [CrossRef]

9. Frost, H.M. A 2003 update of bone physiology and Wolff's Law for clinicians. Angle Orthod. 2004, 74, 3-15. [CrossRef] [PubMed]

10. Wolff, J. The Law of Bone Remodeling; Springer Verlag: Berlin, Germany, 1986.

11. Edelhoff, D.; Beuer, F.; Schweiger, J.; Brix, O.; Stimmelmayr, M.; Guth, J.F. CAD/CAM-generated high-density polymer restorations for the pretreatment of complex cases: A case report. Quintessence Int. 2012, 43, 457-467. [PubMed]

12. Bacchi, A.; Consani, R.L.; Mesquita, M.F.; Dos Santos, M.B. Effect of framework material and vertical misfit on stress distribution in implant-supported partial prosthesis under load application: 3-D finite element analysis. Acta Odontol. Scand. 2013, 71, 1243-1249. [CrossRef] [PubMed]

13. Esaki, D.; Matsushita, Y.; Ayukawa, Y.; Sakai, N.; Sawae, Y.; Koyano, K. Relationship between magnitude of immediate loading and peri-implant osteogenesis in dogs. Clin. Oral. Implants. Res. 2012, 23, 1290-1296. [CrossRef] [PubMed]

14. Crespi, R.; Cappare, P.; Gherlone, E.; Romanos, G.E. Immediate versus delayed loading of dental implants placed in fresh extraction sockets in the maxillary esthetic zone: A clinical comparative study. Int. J. Oral Maxillofac. Implant. 2008, 23, 753-758.

15. Embery, G.; Waddington, R.J.; Hall, R.C.; Last, K.S. Connective tissue elements as diagnostic aids in periodontology. Periodontol 2000 2000, 24, 193-214. [CrossRef] [PubMed]

16. Nanci, A.; Bosshardt, D.D. Structure of periodontal tissues in health and disease. Periodontol 2000 2006, 40, 11-28. [CrossRef] [PubMed]

17. Ten Cate, A.R. Oral Histology: Development, Structure, and Function; Mosby: St Louis, MO, USA, 1998 ; p. 497.

18. Papadopoulou, K.; Keilig, L.; Eliades, T.; Krause, R.; Jager, A.; Bourauel, C. The time-dependent biomechanical behaviour of the periodontal ligament-An in vitro experimental study in minipig mandibular two-rooted premolars. Eur. J. Orthod. 2014, 36, 9-15. [CrossRef] [PubMed]

19. Mühlemann, H.R. Ten years of tooth mobility measurements. J. Periodontol. 1960, 25, 128-137. [CrossRef]

20. Kogawa, E.M.; Calderon, P.S.; Lauris, J.R.; Araujo, C.R.; Conti, P.C. Evaluation of maximal bite force in temporomandibular disorders patients. J. Oral. Rehabil. 2006, 33, 559-565. [CrossRef] [PubMed]

21. Bakke, M.; Holm, B.; Jensen, B.L.; Michler, L.; Moller, E. Unilateral, isometric bite force in 8-68-year-old women and men related to occlusal factors. Scand. J. Dent. Res. 1990, 98, 149-158. [CrossRef] [PubMed]

22. Braun, S.; Bantleon, H.P.; Hnat, W.P.; Freudenthaler, J.W.; Marcotte, M.R.; Johnson, B.E. A study of bite force, part 1: Relationship to various physical characteristics. Angle Orthod. 1995, 65, 367-372. [CrossRef] [PubMed]

23. Varga, S.; Spalj, S.; Lapter Varga, M.; Anic Milosevic, S.; Mestrovic, S.; Slaj, M. Maximum voluntary molar bite force in subjects with normal occlusion. Eur. J. Orthod. 2011, 33, 427-433. [CrossRef] [PubMed]

24. Helkimo, E.; Carlsson, G.E.; Helkimo, M. Bite force and state of dentition. Acta Odontol. Scand. 1977, 35, $297-303$. [CrossRef] [PubMed]

25. Gibbs, C.H.; Anusavice, K.J.; Young, H.M.; Jones, J.S.; Esquivel-Upshaw, J.F. Maximum clenching force of patients with moderate loss of posterior tooth support: A pilot study. J. Prosthet. Dent. 2002, 88, 498-502. [CrossRef] [PubMed]

(C) 2018 by the authors. Licensee MDPI, Basel, Switzerland. This article is an open access article distributed under the terms and conditions of the Creative Commons Attribution (CC BY) license (http://creativecommons.org/licenses/by/4.0/). 